\title{
Financial Impact of the Robotic Approach in Liver Surgery: A Comparative Study of Clinical Outcomes and Costs Between the Robotic and Open Technique in a Single Institution
}

\author{
Despoina Daskalaki, MD, Raquel Gonzalez-Heredia, MD, PhD, Marc Brown, CFA, \\ Francesco M. Bianco, MD, Ivo Tzvetanov, MD, Myriam Davis, NP, \\ Jihun Kim, MD, Enrico Benedetti, MD, and Pier C. Giulianotti ${ }^{1}$
}

\begin{abstract}
Background: One of the perceived major drawbacks of minimally invasive techniques has always been its cost. This is especially true for the robotic approach and is one of the main reasons that has prevented its wider acceptance among hospitals and surgeons. The aim of our study was to evaluate the clinical outcomes and economic impact of robotic and open liver surgery in a single institution.

Methods: Sixty-eight robotic and 55 open hepatectomies were performed at our institution between January 1, 2009 and December 31, 2013. Demographics, perioperative data, and postoperative outcomes were collected and compared between the two groups. An independent company performed the financial analysis. The economic parameters comprised direct variable costs, direct fixed costs, and indirect costs.

Results: Mean estimated blood loss was significantly less in the robotic group (438 versus $727.8 \mathrm{~mL} ; P=.038$ ). Overall morbidity was significantly lower in the robotic group (22\% versus $40 \% ; P=.047)$. Clavien III/IV complications were also lower, with $4.4 \%$ in the robotic versus $16.3 \%$ in the open group $(P=.043)$. The length of stay in the intensive care unit (ICU) was shorter for patients who underwent a robotic procedure (2.1 versus 3.3 days; $P=.004$ ). The average total cost, including readmissions, was $\$ 37,518$ for robotic surgery and $\$ 41,948$ for open technique.

Conclusions: Robotic liver resections had less overall morbidity, ICU, and hospital stay. This translates into decreased average costs for robotic surgery. These procedures are financially comparable to open resections and do not represent a financial burden to the hospital.
\end{abstract}

Keywords: liver surgery, cost, robotic surgery

\section{Introduction}

M INIMALlY INVASIVE SURGERY (MIS) for liver resections has been slowly adopted over the last two decades, but currently represents a possible alternative to the open technique, for some indications. ${ }^{1-8}$ The advantages provided by MIS are well established in the current literature. ${ }^{1,7-9}$ Clinical and oncologic outcomes have proven to be equivalent to traditional open surgery, when performed by expert hands. ${ }^{1-6,9-16}$ Moreover, robotic technique could overcome some of the limitations of laparoscopy, allowing for completion in a minimally invasive manner for a greater percentage of complex cases. ${ }^{7,17-23}$

One of the perceived major drawbacks of the minimally invasive techniques has always been its cost. ${ }^{24-27}$ This is especially true for the robotic approach and is one of the main reasons that have prevented its wider acceptance among hospitals and surgeons. ${ }^{28-30}$ Several published articles have

\footnotetext{
${ }^{1}$ Division of General, Minimally Invasive, and Robotic Surgery, Department of Surgery, University of Illinois at Chicago, Chicago, Illinois.

${ }^{2}$ AlixPartners, Chicago, Illinois.

${ }^{3}$ Division of Transplantation, Department of Surgery, University of Illinois at Chicago, Chicago, Illinois.

(C) Despoina Daskalaki et al. 2017; Published by Mary Ann Liebert, Inc. This Open Access article is distributed under the terms of the Creative Commons Attribution Noncommercial License (http://creativecommons.org/licenses/by-nc/4.0/) which permits any noncommercial use, distribution, and reproduction in any medium, provided the original author(s) and the source are credited.
} 
assessed the financial impact of laparoscopic liver resections, comparing them to open surgery. ${ }^{8-10,31-33}$ The results that emerged to prove that laparoscopic surgery has an equal or even superior cost efficiency to open surgery. Even though the intraoperative costs are higher, due to the expensive laparoscopic instruments and longer operative times, the lower morbidity and shorter hospital stay reduce the overall hospital costs. ${ }^{8-10,31-33}$

Several studies have evaluated the cost effectiveness of robotic surgery in several fields. ${ }^{24,34-40}$ The financial analyses were mainly performed by the centers conducting the study, which could lead to a potential bias. In urological surgery, when radical prostatectomy is concerned, the robotic approach seems to have higher costs that are not compensated by the reduced hospital stay. ${ }^{38}$ On the contrary, other procedures, such as cystectomy and partial nephrectomy, seem to be more cost-effective. ${ }^{25,38}$ In general surgery, some authors have been shown to lower overall cost by reducing complications, improving operative times, and cutting down on supplies. ${ }^{34-37}$ In more complex cases, such as hepatectomies, the reduction of complications, hospital stay, and readmissions could translate into a real cost benefit, even if the initial acquisition and intraoperative costs are higher.

The aim of our study is to evaluate the clinical outcomes and economic impact of robotic and open liver surgery in a single institution. An independent company performed the financial analysis, eliminating the risk of an observer bias.

\section{Methods}

This is a retrospective, comparative study of data collected as part of standard care. All data regarding patients who underwent robotic and open liver resections at the University of Illinois Hospital \& Health Sciences System between January 1,2009 and December 31, 2013 were collected and entered into a database. The data include patients' demographics, intraoperative findings, postoperative outcomes, and all associated costs. An independent company (AlixPartners [AP]) was contracted to perform the economic evaluation of the data. An institutional review board approved the study protocol (IRB Protocol No. 2014-0780).

Inclusion criteria consisted of all adult patients who underwent robotic and open liver resection for any indication. Bulky lesions infiltrating the diaphragm and vascular encasement were the only absolute contraindications for the robotic approach. The total number of procedures performed was 123 , of which 55 were open and 68 robotic resections. They were all consecutive cases. Both groups were comparable in terms of age, body mass index, American Society of Anesthesiologists score, and previous abdominal surgery rate (Table 1).

Major hepatectomy was defined as the resection of three or more hepatic segments. In the robotic group, there were 29 major $(42.7 \%)$ and 39 minor $(57.3 \%)$ resections performed, and in the open group there were 24 major (43.6\%) and 31 minor resections (56.4\%), respectively.

All robotic cases were performed by one experienced robotic, hepatobiliary surgeon. The robotic system used for all procedures was the da Vinci Si Surgical System (Intuitive Surgical, Sunnyvale, CA). The technical details of the robotic hepatectomy have been previously described. ${ }^{4,19}$ The open cases were performed by five experienced hepatobiliary/ transplant surgeons. All consecutive patients seen by the
Table 1. Patient Demographics and Preoperative Data

\begin{tabular}{|c|c|c|c|}
\hline Approach & Robotic & Open & $\mathrm{P}$ \\
\hline $\begin{array}{l}\text { Total number } \\
\text { of patients }\end{array}$ & 67 & 54 & \\
\hline $\begin{array}{l}\text { Total number } \\
\text { of procedures }\end{array}$ & $68^{a}$ & 55 & \\
\hline $\begin{array}{l}\text { Gender: male/ } \\
\text { female, } n\end{array}$ & $31 / 37$ & $25 / 30$ & $>.05$ \\
\hline $\begin{array}{l}\text { Mean age, } \\
\text { years (range) }\end{array}$ & $52.5(20-78)$ & $54.3(22-52)$ & $>.05$ \\
\hline $\begin{array}{l}\text { Mean BMI, } \\
\mathrm{kg} / \mathrm{m}^{2} \text { (range) }\end{array}$ & $29(16.5-45.6)$ & $28.9(18.6-40)$ & $>.05$ \\
\hline \multicolumn{4}{|l|}{ ASA score, $n(\%)$} \\
\hline $\mathrm{I} / \mathrm{II}$ & $34(50)$ & $28(51)$ & $>.05$ \\
\hline III/IV & $34(50)$ & $27(49)$ & \\
\hline $\begin{array}{l}\text { Previous abdominal } \\
\text { surgery, \% }\end{array}$ & 50 & 58 & $>.05$ \\
\hline $\begin{array}{l}\text { Type of liver } \\
\text { resection, } n(\%)\end{array}$ & & & $>.05$ \\
\hline Major & $29(42.7)$ & $24(43.6)$ & \\
\hline Minor & $39(57.3)$ & $31(56.4)$ & \\
\hline $\begin{array}{l}\text { Associated procedure } \\
\text { performed, } n(\%)\end{array}$ & 12 (17.6) & $9(16.3)$ & $>.05$ \\
\hline $\begin{array}{l}\text { Right hepatectomy, } \\
n(\%)\end{array}$ & $21(72.4)$ & $11(45.8)$ & \\
\hline $\begin{array}{l}\text { Left hepatectomy, } \\
n(\%)\end{array}$ & $2(7)$ & $4(16.7)$ & \\
\hline $\begin{array}{l}\text { Three or more } \\
\text { segments, } n(\%)\end{array}$ & $1(3.4)$ & $4(16.7)$ & \\
\hline $\begin{array}{l}\text { Extended right } \\
\quad \text { hepatectomy, } n(\%)\end{array}$ & $4(13.8)$ & $4(16.7)$ & \\
\hline $\begin{array}{l}\text { Extended left } \\
\quad \text { hepatectomy, } n(\%)\end{array}$ & $1(3.4)$ & $1(4.1)$ & \\
\hline
\end{tabular}

${ }^{\mathrm{a}}$ One of which was a hybrid robotic-open procedure.

ASA, American Society of Anesthesiologists; BMI, body mass index.

robotic, HPB surgeon were done robotically, and all patients seen by the transplant division were done open. None of the surgeons was at the beginning of their learning curve.

\section{Financial analysis}

AP was engaged by the University of Illinois, Department of Surgery (UIDS) to provide planning, analysis, and assistance related to a study comparing financial costs between robotic and open liver resection surgeries performed by UIDS personnel. UIDS assigned each patient subject an anonymous patient code and provided the data to AP. They analyzed these data from a financial perspective, summarizing pertinent information on both an annual and average basis. In the course of the analysis, they also arrayed and summarized patient clinical statistics. Specific surgery-related metrics included operating room time, estimated blood loss, transfusion rate, intraoperative complications, days in the intensive care unit (ICU), and hospital readmission.

UIDS breaks out its departmental expenses into three primary categories: direct variable costs, direct fixed costs, and indirect costs. Costs from each of the three categories were incorporated in the surgical cost comparison analysis (direct variable costs include direct variable labor, direct variable supplies, and other direct variable costs; direct fixed 
costs include direct fixed labor, direct fixed supplies, direct fixed capital charges, and other direct fixed costs; indirect costs include on behalf of expenses and other indirect costs). All costs (including cost of the robotic system, maintenance, depreciation expenses, personnel wages, medical education costs, and general service contracts for a department) were included in the analysis (Supplementary Table S1; Supplementary Data are available online at www.liebertpub.com/ lap). To observe any variance in the comparison between the surgical procedure and the total medical care provided related to the surgery, the cost comparison analysis was performed from two perspectives: including costs associated with readmissions and excluding costs associated with readmissions. Cost data based on the population indicated that, on a financial comparative basis, the average cost of an open surgery was greater than the average cost of a robotic surgery. This was true of costs analyzed, when both including and excluding readmission costs.

Certain patients in the population incurred costs that were significantly higher than the average cost of the population, which had the potential to impact the cost comparison. As such, we conducted analyses isolating these higher cost patients to observe the impact, if any, on the overall study findings. A total cost of $\$ 100,000$ per patient was utilized as a threshold in isolating potential high-cost patients for analytic purposes. Three robotic surgery patients in the population were considered high-cost patients and 4 open surgery patients in the population were considered high-cost patients.

In addition, we reviewed and analyzed the individual cost categories that contributed to the total cost of open and robotic surgery. We looked for cost categories that represented a meaningful percentage of the total cost of the surgery. Six categories of costs constituted greater than $3 \%$ of the total direct and indirect surgery costs. We further analyzed these six cost categories on a nonstatistical basis to compare any cost difference between open and robotic surgeries relative to the six cost drivers.

The six categories of cost were anesthesiology, operating room/recovery room, ICU, inpatient nursing, inpatient pharmacy, and readmission costs. Each cost category was analyzed on an average basis relative to the number of applicable surgeries. On average, there was no real difference in anesthesiology costs between the two surgery types. The difference in operating room/recovery room costs, on average favored open surgery, but the differential in ICU costs heavily favored the robotic surgery technique.

\section{Statistical analysis}

Categorical variables were compared using a chi-square test or Fisher's exact test, where appropriate. Continuous variables were compared using the independent $t$-test. $P$-value $<.05$ was considered statistically significant.

Statistical and regression analyses were used to determine whether the overall cost relationships between open and robotic surgery were statistically significant. Three types of regression models were performed for hypothesis testing.

The first regression, ordinary least squares (OLS), assessed the relationship between costs and the two types of procedures while controlling other discrete and continuous factors. A second model, a probit regression, was performed to assess the likelihood that certain factors which influence cost also influ- enced treatment type (the variable of interest in the OLS regression), thereby potentially biasing the OLS estimates. Finally, an endogenous treatment-effects regression model was performed to take into account the specific correlation structure between the factors that affect the procedure type and the factors that affect the costs.

The null hypothesis of no difference in costs between the two procedure types was not rejected in the OLS regression or the endogenous treatment regression model. A significance level of .05 was used for all hypothesis testing. Resulting $P$-values from each regression model were evaluated in comparison to this significance level. Data analyses were conducted using SPSS 22.0 (IBM, SPSS Statistics) and STATA/SE 12.1 (StataCorp LP, College Station, TX).

\section{Results}

\section{Clinical outcomes}

Demographics, preoperative data, intraoperative results, and postoperative outcomes were analyzed and compared between the robotic and open group (Table 1). The mean

TABle 2. Intraoperative Results

\begin{tabular}{|c|c|c|c|}
\hline Approach & Robotic & Open & $\mathrm{P}$ \\
\hline \multicolumn{4}{|l|}{ Overall } \\
\hline $\begin{array}{l}\text { Mean operative } \\
\text { time, minutes }\end{array}$ & 293.4 & 256 & $>.05$ \\
\hline $\begin{array}{l}\text { Mean estimated } \\
\text { blood loss, } \mathrm{mL}^{\mathrm{a}}\end{array}$ & 438 & 727.8 & .038 \\
\hline $\begin{array}{l}\text { Overall transfusion } \\
\text { rate }\end{array}$ & $20.5 \%(14 / 68)$ & $21.8 \%(12 / 55)$ & $>.05$ \\
\hline $\begin{array}{l}\text { Mean units of } \\
\text { PRBCs } \\
\text { transfused }\end{array}$ & 4.2 & 3.2 & $>.05$ \\
\hline Transfusion rate $\mathrm{a}^{\mathrm{a}}$ & $13.2 \%(9 / 68)$ & $21.8 \%$ & $>.05$ \\
\hline $\begin{array}{l}\text { Conversion to } \\
\text { open, } n(\%)\end{array}$ & $6(8.8)$ & - & \\
\hline $\begin{array}{l}\text { Intraoperative } \\
\text { complications, } \\
n(\%)\end{array}$ & $2(2.9)$ & $2(3.6)$ & $>.05$ \\
\hline \multicolumn{4}{|l|}{ Major } \\
\hline $\begin{array}{l}\text { Mean operative } \\
\text { time, minutes }\end{array}$ & 404 & 309 & .004 \\
\hline $\begin{array}{l}\text { Mean estimated } \\
\text { blood loss, } \mathrm{mL}^{\mathrm{a}}\end{array}$ & 570 & 1018.7 & .051 \\
\hline $\begin{array}{l}\text { Overall transfusion } \\
\text { rate }\end{array}$ & $34.4 \%(10 / 29)$ & $33 \%(8 / 24)$ & $>.05$ \\
\hline Transfusion rate ${ }^{\mathrm{a}}$ & $20.6 \%(6 / 29)$ & $33 \%$ & $>.05$ \\
\hline $\begin{array}{l}\text { Conversion to } \\
\quad \text { open, } n(\%)\end{array}$ & $5(17.2)$ & - & - \\
\hline \multicolumn{4}{|l|}{ Minor } \\
\hline $\begin{array}{l}\text { Mean operative } \\
\text { time, minutes }^{\mathrm{a}}\end{array}$ & 223.2 & 215 & $>.05$ \\
\hline $\begin{array}{l}\text { Mean estimated } \\
\text { blood loss, } \mathrm{mL}^{\mathrm{a}}\end{array}$ & 354.7 & 510 & $>.05$ \\
\hline $\begin{array}{l}\text { Overall transfusion } \\
\text { rate }\end{array}$ & $10.2 \%(4 / 39)$ & $12.9 \%(4 / 31)$ & $>.05$ \\
\hline Transfusion rate $^{\mathrm{a}}$ & $7.6 \%(3 / 39)$ & $12.9 \%$ & $>.05$ \\
\hline $\begin{array}{l}\text { Conversion to } \\
\text { open, } n(\%)\end{array}$ & $1(2.5)$ & 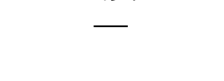 & - \\
\hline
\end{tabular}

${ }^{a}$ Excluding conversions-to-open.

LOS, length of stay, PRBCs, packed red blood cells. 
operative time was 293.4 minutes (range: 90-660) in the robotic group and 256 minutes (range: $50-485$ ) in the open group, without a significant statistical difference $(P>.05)$. The mean estimated blood loss was $438 \mathrm{~mL}$ (range: $30-5000$ ) and $727.8 \mathrm{~mL}$ (range: 10-3500) in the robotic and open group, respectively, with a difference that reached statistical significance $(P=.038)$. The overall intraoperative transfusion rate was $20.5 \%$ in the robotic group, $13.2 \%$ in the robotic group, excluding the conversions to open, and $21.8 \%$ in the open group $(P>.05)$. Six patients required a conversion to open surgery $(8.8 \%)$. Two patients in each group had an intraoperative complication $(2.9 \%$ and $3.6 \%$ in the robotic and open group, respectively).

Intraoperative complications included two cases of bleeding that required extensive hemostasis (robotic group), a case of pneumothorax with 12th rib fracture and a severe hypotensive episode requiring phenylephrine to support blood pressure (open group). No statistical significance was found when the intraoperative results for major and minor hepatectomies were analyzed separately, with the exception of mean operative time in major hepatectomies (404 minutes in the robotic group versus 309 in the open group, $P=.004$ ). The mean blood loss in major hepatectomies was $570 \mathrm{~mL}$ (range: $80-1900)$ and $1018.7 \mathrm{~mL}$ (range: $150-3500)$ with the robotic and open approach, respectively $(P=.051)$. All intraoperative results are summarized in Table 2.

The overall morbidity was $22 \%$ and $40 \%$ in the robotic and open group, which was statistically significant $(P=.047)$. When patients who underwent a conversion to open were excluded, the morbidity was $14.7 \%(P=.011)$. Three patients presented with a Clavien IIIa complication in the robotic group (4.4\%), no Clavien IV complications, and the 30-day mortality was nil. ${ }^{41}$ In the open group, 7 patients presented with a Clavien IIIa complication (12.7\%) and 2 a Clavien IV ( $1 \mathrm{IVa}$ and $1 \mathrm{IVb}$ ). The difference between Clavien III/IV complications in the two groups was statistically significant (4.4\% versus $16.4 \% ; P=.043$ ) (Table 3 ).

The most common postoperative complication in the robotic group was pulmonary $(7.3 \%)$. Biliary leak occurred in 3 patients $(4.4 \%)$, of which 2 had a conversion to open. Other complications included arrhythmias, postoperative bleed, postoperative ileus, and liver failure. Pulmonary complications

Table 3. Postoperative Outcomes

\begin{tabular}{|c|c|c|c|}
\hline Approach & Robotic & Open & $\mathrm{P}$ \\
\hline \multicolumn{4}{|l|}{ Overall } \\
\hline Overall morbidity, $n(\%)$ & $15(22)$ & $22(40.0)$ & .047 \\
\hline Clavien I/II, $n(\%)$ & $12(17.6)$ & $13(23.6)$ & $>.05$ \\
\hline Clavien III/IV, $n(\%)$ & $3(4.4)$ & $9(16.3)$ & .043 \\
\hline Morbidity, $n(\%)^{\mathrm{a}}$ & $10(14.7)$ & $22(40.0)$ & .006 \\
\hline Mean LOS in complicated patients (range) & $11.7(5-27)$ & $13.8(4-51)$ & $>.05$ \\
\hline Mean LOS in complicated patients (range) ${ }^{\mathrm{a}}$ & $9.3(5-21)$ & - & $>.05$ \\
\hline Overall mean LOS (range) & $6.8(2-27)$ & $9.2(3-51)$ & $>.05$ \\
\hline Mean LOS ${ }^{\mathrm{a}}$ & 6 & 9.2 & .011 \\
\hline Postoperative stay in ICU, $n(\%)$ & $57(83.8)$ & $40(72.7)$ & $>.05$ \\
\hline Mean overall length of stay in ICU, days (range) & $2.5(1-26)$ & $3.3(1-9)$ & $>.05$ \\
\hline Mean length of stay in ICU, days (range) ${ }^{\mathrm{a}}$ & $2.1(1-5)$ & 3.3 & .004 \\
\hline Overall readmission rate, $n(\%)$ & $4(5.8)$ & $5(9)$ & $>.05$ \\
\hline Readmission rate, $n(\%)^{\mathrm{a}}$ & $2(2.9)$ & $5(9)$ & $>.05$ \\
\hline 30-Day mortality, $n(\%)$ & 0 & $1(1.8)$ & $>.05$ \\
\hline Reoperation rate & 0 & 0 & $>.05$ \\
\hline Final pathology: malignant/benign & $38 / 30$ & $45 / 10$ & .003 \\
\hline \multicolumn{4}{|l|}{ Major } \\
\hline Overall morbidity, $n(\%)$ & $9(31)$ & $9(37.5)$ & $>.05$ \\
\hline Clavien I/II, $n(\%)$ & $7(24)$ & $5(20.8)$ & $>.05$ \\
\hline Clavien III/IV, $n(\%)$ & $2^{\mathrm{b}}(6.8)$ & $4(16.6)$ & $>.05$ \\
\hline Morbidity ${ }^{\mathrm{a}}$ & $4(13.7)$ & $9(37.5)$ & $>.05$ \\
\hline Mean LOS (range) & $8.8(3-27)$ & $9.3(4-51)$ & $>.05$ \\
\hline Mean LOS (range) ${ }^{\mathrm{a}}$ & $7.2(3-21)$ & 9.3 & $>.05$ \\
\hline Postoperative stay in ICU, $n(\%)$ & $27(93.1)$ & $19(79.1)$ & $>.05$ \\
\hline Mean overall length of stay in ICU, days (range) & $3.3(1-26)$ & $3.5(2-8)$ & $>.05$ \\
\hline Mean length of stay in ICU, days (range) ${ }^{b}$ & $2.4(1-5)$ & 3.5 & $>.05$ \\
\hline Final pathology: malignant/benign & $18 / 11$ & $19 / 5$ & $>.05$ \\
\hline \multicolumn{4}{|l|}{ Minor } \\
\hline Overall morbidity, $n(\%)$ & $6(15.3)$ & 13 (41.9) & .017 \\
\hline Clavien I/II, $n(\%)$ & $5(12.8)$ & $8(25.8)$ & $>.05$ \\
\hline Clavien III/IV, $n(\%)$ & $1(2.5)$ & $5(16.1)$ & $>.05$ \\
\hline Mean LOS (range) & $5.2(2-11)$ & $9(3-38)$ & .013 \\
\hline Postoperative stay in ICU, $n(\%)$ & $30(76.9)$ & $21(67.7)$ & $>.05$ \\
\hline Mean overall length of stay in ICU, days (range) & $1.9(1-4)$ & $3.1(1-8)$ & .021 \\
\hline Final pathology: malignant/benign & $20 / 19$ & $26 / 5$ & .005 \\
\hline
\end{tabular}

${ }^{\mathrm{a}}$ Excluding converted patients.

${ }^{\mathrm{b}}$ Both patients were converted-to-open.

ICU, intensive care unit; LOS, length of stay. 
were also the most frequent in the open group (16.3\%), followed by biliary leaks (9\%) and postoperative bleed $(5.4 \%)$ (Table 4). The 30-day mortality rate in the open group was $1.8 \%$ (1 patient with hepatocellular carcinoma who underwent a right hepatectomy and was discharged without complications). None of the patients required a reoperation in either group. The overall mean hospital stay was 6.8 days (range: $2-$ $27)$ in the robotic and 9.2 days (range: $3-51$ ) in the open group $(P>.05)$.

The mean overall hospital stay of the patients with a postoperative complication was 11.7 days (range: 5-27) and 13.8 days (range: $4-51$ ) in the robotic and open group, respectively $(P>.05)$. Eighty-three percent of patients who underwent a robotic resection were admitted in the ICU postoperatively and $72.7 \%$ after open resection $(P>.05)$. Patients in the ICU were managed by an autonomous team of intensivists. The mean length of stay in ICU was 2.5 days (range: $1-26)$ versus 3.3 days (range: $1-9)$ in the robotic and open group $(P>.05)$. This value assumes statistical significance when patients who were converted to open are excluded, with a mean length of ICU stay of 2.1 days (range 1-5) versus 3.3 days $(P=.004)$. The overall readmission rates were $5.8 \%$ and $9 \%$ for the robotic and open group, respectively $(P>.05)$. Final pathology confirmed a malignant disease in $55.8 \%$ of the robotic cases and $81.8 \%$ in the open ones $(P=.003)$.

No statistically significant differences between the two groups were found when the postoperative outcomes of major hepatectomies were analyzed independently. The morbidity rate after minor hepatectomy was higher in the open group (41.9\% versus $15.3 \% ; P=.017$ ). The length of hospital stay was significantly lower in the robotic group, with a mean of 5.2 days (range: $2-11$ ) versus 9 days (range: $1-8$ ) in the open group $(P=.013)$. The length of postoperative stay in ICU was also lower in the robotic group, with a mean of 1.9 days (range: $1-4$ ) versus 3.1 days (range: $1-8 ; P=.021$ ). The postoperative outcomes of major and minor hepatectomies are summarized in Table 3.

\section{Financial results}

This analysis demonstrated that over the course of the study, anesthesiology, operating room/recovery room, and readmission costs were, on average, higher for robotic sur-

Table 4. Postoperative Complications IN THE RoBotic AND OpEN GROUPS

\begin{tabular}{lcc}
\hline Variable & $\begin{array}{c}\text { Robotic } \\
\text { group }\end{array}$ & $\begin{array}{c}\text { Open } \\
\text { group }\end{array}$ \\
\hline $\begin{array}{l}\text { Biliary leak, } n(\%) \\
\text { Pulmonary } \\
\quad \text { complications, } n(\%)\end{array}$ & $3^{\mathrm{a}(4.4)}$ & $5(9)$ \\
$\begin{array}{l}\text { Cardiologic } \\
\quad \text { complications, } n(\%)\end{array}$ & $5(7.3)$ & $9(16.3)$ \\
$\begin{array}{l}\text { Postoperative } \\
\quad \text { bleeding, } n(\%)\end{array}$ & $2(2.9)$ & $3(5.4)$ \\
$\begin{array}{l}\text { Postoperative ileus, } n(\%) \\
\text { Liver failure, } n(\%)\end{array}$ & $2(2.9)$ & - \\
$\begin{array}{l}\text { Sepsis, } n(\%) \\
\text { Ascites, } n(\%)\end{array}$ & $1(1.4)$ & $1(1.8)$ \\
Hepatic abscess, $n(\%)$ & - & $1(1.8)$ \\
\hline
\end{tabular}

${ }^{\mathrm{a}}$ Two of these patients were converted-to-open.
Table 5. Specific Costs Divided by Category

Average cost/

surgery (USD)

\begin{tabular}{lr}
\hline Anesthesiology & \\
Open & 1432 \\
Robotic & 1444 \\
Difference & 12 \\
Operating room/recovery room & \\
Open & 11,958 \\
Robotic & 14,665 \\
Difference & 2707 \\
ICU & \\
Open & 12,417 \\
Robotic & 6159 \\
Difference & 6258 \\
Inpatient nursing & \\
Open & 4217 \\
Robotic & 3566 \\
Difference & 651 \\
Inpatient pharmacy & \\
Open & 2721 \\
Robotic & 1854 \\
Difference & 867 \\
Readmission costs & \\
Open & 22,263 \\
Robotic & 25,125 \\
Difference & 2862 \\
Total other costs & \\
Open & 13,527 \\
Robotic & 11,378 \\
Difference & 2149 \\
\hline & \\
\hline &
\end{tabular}

ICU, intensive care unit; USD, US dollars.

geries than for open surgeries and that ICU, inpatient nursing, and inpatient pharmacy costs were, on average, higher for open surgeries than for robotic surgeries. The costs for each category are found in Table 5.

The average total cost, including readmissions, was $\$ 37,518$ for robotic surgery and $\$ 41,948$ for open. Excluding readmission costs, the total robotic surgery cost was $\$ 36,040$ and the total open surgery cost was $\$ 39,924$. There was no statistically significant difference between the two types of procedures (Table 6). All total average costs were also analyzed separately for each year, from 2009 to 2013, but no significant difference was found. Three patients of the robotic group and 4 of the open were identified as high-cost patients. The first 3 were patients converted to open, complicated by biliary leak. The remaining 4 were patients with a complicated

Table 6. Total Cost of Open and Robotic Liver Resections

\begin{tabular}{lcc}
\hline Total cost $(U S D)$ & $\begin{array}{c}\text { Including } \\
\text { readmission }\end{array}$ & $\begin{array}{c}\text { Excluding } \\
\text { readmission }\end{array}$ \\
\hline $\begin{array}{l}\text { Average cost of } \\
\text { open surgery }\end{array}$ & 41,948 & 39,924 \\
$\begin{array}{l}\text { Average cost of } \\
\text { robotic surgery }\end{array}$ & 37,518 & 36,040 \\
$\begin{array}{l}\text { Difference } \\
\text { T-Stat }\end{array}$ & 4430 & 3884 \\
\hline
\end{tabular}


Table 7. Total Cost of Open and Robotic Liver Resections in High- and Non-High-Cost Patients

\begin{tabular}{|c|c|c|c|c|c|c|c|}
\hline \multicolumn{4}{|c|}{ Non-high-cost patients $(<\$ 100,000$ total cost $)$} & \multicolumn{4}{|c|}{ High-cost patients $(>\$ 100,000$ total cost $)$} \\
\hline & Cases (n) & Total cost & Average cost & & Cases (n) & Total cost & Average cost \\
\hline \multicolumn{8}{|c|}{ Including readmission } \\
\hline Robotic & 65 & $2,125,737$ & 32,704 & Robotic & 3 & 425,475 & 141,825 \\
\hline Open & 51 & $1,670,363$ & 32,752 & Open & 4 & 636,775 & 159,194 \\
\hline \multicolumn{8}{|c|}{ Excluding readmission } \\
\hline Robotic & 65 & $2,107,567$ & 32,424 & Robotic & 3 & 343,144 & 114,381 \\
\hline Open & 51 & $1,616,172$ & 31,690 & Open & 4 & 579,651 & 144,913 \\
\hline
\end{tabular}

postoperative course and a mean hospital stay of 34 days (range: 22-51).

When the high-cost patients $(>\$ 100,000$ total cost) were separated from the remainder of the population, the average cost of open surgery was similar to that of robotic surgery, when accounting for the costs associated with readmission (\$32,704 for the robotic group versus $\$ 32,752$ for the open group). The average cost of open surgery for the remaining patient population dropped below that of robotic surgery when excluding the costs associated with readmission $(\$ 32,424$ for the robotic group versus $\$ 31,690$ for the open group) (Table 7).

\section{Discussion}

Minimally invasive hepatic resections have undergone a steady increase in the past two decades. ${ }^{1,3,8}$ Postoperative and oncologic outcomes have proven to be as effective as with traditional open surgery, when performed by experienced surgeons, for both laparoscopic and robotic hepatectomies. ${ }^{-3,5,11,12,14,19,42}$ Laparoscopy seems to be more widely performed for wedge resections and other minor hepatectomies, since major resections can be very challenging and left only in the hands of a few experts. ${ }^{1,7,14}$ Robot-assisted surgery can overcome some of the limits of laparoscopy, preserving the advantages of the minimally invasive approach. In a recent article comparing robotic and laparoscopic hepatectomies, the authors stated that the robotic technique allowed them to complete a larger number of liver resections, both major and minor, in a totally minimally invasive manner. ${ }^{7}$

Our study included patients who underwent both major and minor resections in similar percentages in both groups. There were no significant differences in terms of operative time, transfusion rates, and intraoperative complications when the overall results were considered. Interestingly, when major and minor hepatectomies were analyzed separately, there was no statistically significant difference regarding the mean estimated blood loss. While in the minor hepatectomies the results were indeed similar $(354.7 \mathrm{~mL}$ for the robotic and $510 \mathrm{~mL}$ for the open group; $P>.05)$, in the major hepatectomies there was an important difference $(570 \mathrm{~mL}$ in the robotic versus 1018.7 in the open group; $P=.051)$. We believe that it did not reach statistical significance because of the sample size.

The postoperative outcomes showed a significant overall lower rate of complications in the robotic cohort, even when the patients who were converted to open were included $(22 \%$ versus $40 \% ; P=.047)$. When complications were divided into minor (Clavien I-II) and major (Clavien III-IV), we noticed that the results were similar in the first group, but significantly different in the latter. Major complications were significantly lower in the robotic cohort (4.4\% versus $16.4 \%$; $P=$.043). Interestingly, there were only three biliary leaks in the robotic group (4.4\%), two of which were in patients who underwent a conversion-to-open, making the "pure robotic" rate of biliary leak $1.4 \%$. Pulmonary complications were more than twofold more frequent in the open group $(16.3 \%$ versus $7.3 \%$ ).

Postoperative mortality was nil in the robotic group and $1.8 \%$ in the open, in accordance with results found in the literature. ${ }^{2,9}$ At our institution, most of the patients undergoing hepatobiliary procedures are sent to the ICU after surgery, as part of standard care. At the time of the study, $83.8 \%$ of patients who underwent a robotic hepatectomy and $72.7 \%$ of those who underwent an open surgery were transferred to the ICU in the immediate postoperative course. The mean length of stay in the ICU was significantly longer after an open procedure (3.3 versus 2.1 days; $P=.004$ ).

The postoperative results of major hepatectomies confirmed the trend toward a lower major complication rate and shorter hospital and ICU stay in the robotic group, but did not reach statistical significance. On the contrary, when minor hepatectomies were considered, the same parameters were in favor of the robotic group.

It is safe to say that one of the biggest perceived disadvantages of any new technology is the high cost. Substantial criticism has emerged due to the rapid expansion of robotics, especially in the urology field. ${ }^{24-26}$ While robotic prostatectomy currently represents the gold standard, it has not proven to be cost-effective, even when the reduced operative time and shorter hospital stay are considered. ${ }^{38}$ In contrast, in 2012, Hagen et al. evaluated the cost of robotic, laparoscopic, and open Roux-en-Y gastric bypass, including both direct and indirect costs. The authors reported a lower anastomotic leak rate in the robotic group, as well as a reduction of materials used (hand-sewn anastomosis versus laparoscopic stapler), leading to lower overall costs $(\$ 19,363$ robotic versus $\$ 21,697$ laparoscopic versus $\$ 23,000$ open). ${ }^{37}$

Regarding liver surgery, several authors have evaluated the costs related to laparoscopy and open. ${ }^{8,10,31,33,43}$ In a recent meta-analysis, Jackson et al. analyzed the results of all the studies that took into consideration these costs. What emerged is a trend toward higher total operative costs in the case of laparoscopic surgery (\$334.10), but with a trend of higher total hospital costs in the case of open approach (\$3223). Packiam et al. published the only study comparing robotic and laparoscopic liver resections. ${ }^{6}$ This article included only left lateral sectionectomies (11 robotic and 18 laparoscopic). The authors reported a higher rate of minor complications and a longer ICU stay for the patients undergoing robotic resections, 
due to the fact that the authors were at the beginning of their robotic experience, leading them to have a very cautious postoperative regimen.

When only the direct costs were considered, no significant difference was found between the two groups ( $\$ 5130$ for robotic versus $\$ 4408$ for laparoscopic). When the indirect costs of purchasing and maintenance were considered (\$1423 per case), the robotic cases yielded a significantly higher cost ( $\$ 6553$ versus $\$ 4408 ; P=.021$ ). An interesting fact that emerged is that the additional cost of using both laparoscopic and robotic instruments in the robotic cases added an extra cost of only $\$ 302$. A limitation of this study is that it did not take into consideration the overall cost of the inpatient stay.

To the best of our knowledge, this is the first study evaluating the financial impact of robotic and open hepatic resections using an external company, eliminating any observer bias. $^{44}$ Both direct (variable and fixed) and indirect costs were taken into account for the economic analysis. The total costs of open and robotic surgery, including the costs of any readmissions, were $\$ 41,948$ and $\$ 37,518$, respectively. Excluding costs of readmissions, open surgery still had a higher cost $(\$ 39,924$ versus $\$ 36,040)$. The average cost in the "nonhigh-cost" patients $(<\$ 100,000)$ was virtually the same with both techniques (around \$32,700). The average value in the case of high-cost patients was slightly elevated with the open technique $(\$ 159,194$ versus $\$ 141,825)$.

When costs were broken down by category, the average cost per robotic surgery was more expensive in terms of operating room and readmission costs. The total costs resulted in being lower though, because of the cost-effectiveness in terms of ICU, inpatient nursing, and pharmacy costs. Even though a statistical significance in favor of the robotic approach was not reached, it is clear that the high costs associated with purchasing, maintaining, and using the robotic system in the operating room are balanced by a shorter hospital and ICU stay, and less need for postoperative medication.

There are some limitations in our study. This is a retrospective, nonrandomized study. The surgical approach chosen largely depended on the surgeon who evaluated the patient. Nonetheless, there is no selection bias regarding the patients, because the two groups were comparable and all cases were consecutive. We did find a significant difference $(P=.003)$ in malignant versus benign disease. This was mainly seen in the minor hepatectomy group (20 versus 26 cases in the robotic and open group, respectively). Nonetheless, one might argue that malignant disease could increase the postoperative morbidity.

Robotic resections were all performed by a single experienced robotic hepatobiliary surgeon, assisted by an attending surgeon or a robotic surgery fellow. The open resections on the contrary were performed by multiple surgeons. Still they were all experienced hepatobiliary surgeons, assisted by other attendings or senior fellows. Consequently, there were no issues related to the learning curve of any of the surgeons. Moreover, all the patients seen by the robotic surgeon were offered the minimally invasive approach, unless an absolute contraindication was present. Thus, there was no bias such as choosing the simpler cases for the robotic resection.

The results of this study might not be applicable in other centers with less experience in hepatobiliary and/or robotic surgery, or at the beginning of their learning curve. Furthermore, in our institution, laparoscopy was abandoned early on in favor of robotics, so we were not able to compare robotic and laparoscopic liver resections. Even though we proved that robotic liver resections are comparable to open, both regarding clinical outcomes and cost-effectiveness, we do not have enough data to reach conclusions regarding any potential clinical or economic advantages of the robotic over the laparoscopic approach.

Robotic surgery has always been considered a very expensive new technology. Even though, for some procedures, the postoperative advantages do not translate into costeffectiveness, in other more complex cases, the robotic approach could actually prove to be financially beneficial. In conclusion, robotic liver resections in our study had less overall morbidity, ICU and hospital stay. This translated into decreased average costs for robotic surgery. Although this difference was not statistically significant, we have shown that robotic hepatectomies are financially comparable to open resections and do not represent a financial burden to the hospital.

\section{Acknowledgment}

The present research has not been funded in whole or in part by any organization.

\section{Disclosure Statement}

Dr. Pier C. Giulianotti is a consultant for Covidien and Ethicon. The Department of Surgery has a Proctoring Agreement and Grant Support with Intuitive Surgical. The consulting firm AlixPartner was compensated for the financial analysis. The rest of authors declare no conflict of interest pertinent to the study.

\section{References}

1. Nguyen KT, Gamblin TC, Geller DA. World review of laparoscopic liver resection-2,804 patients. Ann Surg 2009; 250:831-841.

2. Nguyen KT, Marsh JW, Tsung A, et al. Comparative benefits of laparoscopic vs open hepatic resection: A critical appraisal. Arch Surg 2011;146:348-356.

3. Milone L, Daskalaki D, Fernandes E, et al. State of the art in robotic hepatobiliary surgery. World J Surg 2013;37: 2747-2755.

4. Giulianotti PC, Sbrana F, Coratti A, et al. Totally robotic right hepatectomy: Surgical technique and outcomes. Arch Surg 2011;146:844-850.

5. Soubrane O, Goumard C, Laurent A, et al. Laparoscopic resection of hepatocellular carcinoma: A French survey in 351 patients. HPB (Oxford) 2014;16:357-365.

6. Packiam V, Bartlett DL, Tohme S, et al. Minimally invasive liver resection: Robotic versus laparoscopic left lateral sectionectomy. J Gastrointest Surg 2012;16:2233-2238.

7. Tsung A, Geller DA, Sukato DC, et al. Robotic versus laparoscopic hepatectomy: A matched comparison. Ann Surg 2014;259:549-555.

8. Bhojani FD, Fox A, Pitzul K, et al. Clinical and economic comparison of laparoscopic to open liver resections using a 2-to-1 matched pair analysis: An institutional experience. J Am Coll Surg 2012;214:184-195.

9. Jackson NR, Hauch A, Hu T, et al. The safety and efficacy of approaches to liver resection: A meta-analysis. JSLS 2015;19:e2014.00186. 
10. Vanounou T, Steel JL, Nguyen KT, et al. Comparing the clinical and economic impact of laparoscopic versus open liver resection. Ann Surg Oncol 2010;17:998-1009.

11. Memeo R, de'Angelis N, Compagnon P, et al. Laparoscopic vs. open liver resection for hepatocellular carcinoma of cirrhotic liver: A case-control study. World J Surg 2014; 38:2919-2926.

12. Dagher I, Belli G, Fantini C, et al. Laparoscopic hepatectomy for hepatocellular carcinoma: A European experience. J Am Coll Surg 2010;211:16-23.

13. Vibert E, Perniceni T, Levard H, et al. Laparoscopic liver resection. Br J Surg 2006;93:67-72.

14. Gobardhan PD, Subar D, Gayet B. Laparoscopic liver surgery: An overview of the literature and experiences of a single centre. Best Pract Res Clin Gastroenterol 2014;28: 111-121.

15. Abood GJ, Tsung A. Robot-assisted surgery: Improved tool for major liver resections? J Hepatobiliary Pancreat Sci 2013;20:151-156.

16. Koffron AJ, Auffenberg G, Kung R, Abecassis M. Evaluation of 300 minimally invasive liver resections at a single institution: Less is more. Ann Surg 2007;246:385392; discussion 392-384.

17. Wu YM, Hu RH, Lai HS, Lee PH. Robotic-assisted minimally invasive liver resection. Asian J Surg 2014;37:53-57.

18. Troisi RI, Patriti A, Montalti R, Casciola L. Robot assistance in liver surgery: A real advantage over a fully laparoscopic approach? Results of a comparative biinstitutional analysis. Int J Med Robot 2013;9:160-166.

19. Giulianotti PC, Coratti A, Sbrana F, et al. Robotic liver surgery: Results for 70 resections. Surgery 2011;149:29-39.

20. Giulianotti PC, Sbrana F, Bianco FM, Addeo P. Robotassisted laparoscopic extended right hepatectomy with biliary reconstruction. J Laparoendosc Adv Surg Tech A 2010;20:159-163.

21. Chen KH, Chen SD, Chen YD, et al. Robotic left hepatectomy with revision of hepaticojejunostomy. Asian J Surg 2014;37:106-109.

22. Spampinato MG, Coratti A, Bianco L, et al. Perioperative outcomes of laparoscopic and robot-assisted major hepatectomies: An Italian multi-institutional comparative study. Surg Endosc 2014;28:2973-2979.

23. Ji WB, Wang HG, Zhao ZM, et al. Robotic-assisted laparoscopic anatomic hepatectomy in China: Initial experience. Ann Surg 2011;253:342-348.

24. Barbash GI, Glied SA. New technology and health care costs-The case of robot-assisted surgery. N Engl J Med 2010;363:701-704.

25. Kaye DR, Mullins JK, Carter HB, Bivalacqua TJ. Robotic surgery in urological oncology: Patient care or market share? Nat Rev Urol 2015;12:55-60.

26. Williams SB, Prado K, Hu JC. Economics of robotic surgery: Does it make sense and for whom? Urol Clin North Am 2014;41:591-596.

27. Hussain A, Malik A, Halim MU, Ali AM. The use of robotics in surgery: A review. Int J Clin Pract 2014;68:1376-1382.

28. Lanfranco AR, Castellanos AE, Desai JP, Meyers WC. Robotic surgery: A current perspective. Ann Surg 2004; 239:14-21.

29. Rondelli F, Balzarotti R, Villa F, et al. Is robot-assisted laparoscopic right colectomy more effective than the conventional laparoscopic procedure? A meta-analysis of short-term outcomes. Int J Surg 2015;18:75-82.
30. Joyce D, Morris-Stiff G, Falk GA, et al. Robotic surgery of the pancreas. World J Gastroenterol 2014;20:1472614732.

31. Abu Hilal M, Di Fabio F, Syed S, et al. Assessment of the financial implications for laparoscopic liver surgery: A single-centre UK cost analysis for minor and major hepatectomy. Surg Endosc 2013;27:2542-2550.

32. Cannon RM, Scoggins CR, Callender GG, et al. Financial comparison of laparoscopic versus open hepatic resection using deviation-based cost modeling. Ann Surg Oncol 2013; 20:2887-2892.

33. Polignano FM, Quyn AJ, de Figueiredo RS, et al. Laparoscopic versus open liver segmentectomy: Prospective, casematched, intention-to-treat analysis of clinical outcomes and cost effectiveness. Surg Endosc 2008;22:2564-2570.

34. Byrn JC, Hrabe JE, Charlton ME. An initial experience with 85 consecutive robotic-assisted rectal dissections: Improved operating times and lower costs with experience. Surg Endosc 2014;28:3101-3107.

35. Bedeir K, Mann A, Youssef Y. Robotic single-site versus laparoscopic cholecystectomy: Which is cheaper? A cost report and analysis. Surg Endosc 2016;30:267-272.

36. Delto JC, Wayne G, Yanes R, et al. Reducing robotic prostatectomy costs by minimizing instrumentation. J Endourol 2015;29:556-560.

37. Hagen ME, Pugin F, Chassot G, et al. Reducing cost of surgery by avoiding complications: The model of robotic Roux-en-Y gastric bypass. Obes Surg 2012;22:52-61.

38. Ahmed K, Ibrahim A, Wang TT, et al. Assessing the cost effectiveness of robotics in urological surgery-A systematic review. BJU Int 2012;110:1544-1556.

39. Wright JD, Ananth CV, Tergas AI, et al. An economic analysis of robotically assisted hysterectomy. Obstet Gynecol 2014;123:1038-1048.

40. Anderson JE, Chang DC, Parsons JK, Talamini MA. The first national examination of outcomes and trends in robotic surgery in the United States. J Am Coll Surg 2012;215: 107-114; discussion 114-106.

41. Dindo D, Demartines N, Clavien PA. Classification of surgical complications: A new proposal with evaluation in a cohort of 6336 patients and results of a survey. Ann Surg 2004;240:205-213.

42. Lai EC, Yang GP, Tang CN. Robot-assisted laparoscopic liver resection for hepatocellular carcinoma: Short-term outcome. Am J Surg 2013;205:697-702.

43. Tsinberg M, Tellioglu G, Simpfendorfer $\mathrm{CH}$, et al. Comparison of laparoscopic versus open liver tumor resection: A case-controlled study. Surg Endosc 2009;23: 847-853.

44. Sham JG, Richards MK, Seo YD, et al. Efficacy and cost of robotic hepatectomy: Is the robot cost-prohibitive? J Robot Surg 2016;10:307-313.

Address correspondence to: Raquel Gonzalez-Heredia, MD, PhD Division of General, Minimally Invasive, and Robotic Surgery University of Illinois at Chicago 840 South Wood Street, 435 E Chicago, IL 60612

E-mail:rgheredi@uic.edu 